Original article

\title{
Impact of the economic crisis on healthcare resources: A panel data analysis in Eastern Mediterranean countries during 2005 to 2013
}

\author{
Ahmad faramarzi $^{\mathrm{a}}$, Javad Javan-Noughabi ${ }^{\mathrm{b}, \mathrm{d}, *}$, Ahmad Sadeghi $^{\mathrm{c}}$, Aziz Rezapour ${ }^{\mathrm{b}, \mathrm{d}}$ \\ ${ }^{a}$ Department of Health Management and Economics, School of Public Health, Tehran University of Medical Sciences, Tehran, Iran \\ ${ }^{\mathrm{b}}$ Health Management and Economics Research Center, Iran University of Medical Sciences, Tehran, Iran \\ ${ }^{c}$ Department of Public Health, Esfarayen Faculty of Medical Sciences, Esfarayen, Iran \\ ${ }^{\mathrm{d}}$ Department of Health Economics, School of Health Management and Information Sciences, Iran University of Medical Sciences, Tehran, Iran
}

\section{A R T I C L E I N F O}

\section{Keywords:}

Economic recession

Health resources

Public health

\begin{abstract}
A B S T R A C T
Background: Studying the impact of economic crisis on healthcare resources is important because the economic crisis is an important socio-economic determinant of healthcare resources and is strongly linked to a number of health outcomes. We aimed to examine the impact of the economic crisis on healthcare resources in the Eastern Mediterranean countries of World Health Organization (WHO).

Methods: In this study, health expenditure per capita was considered as the indicator of healthcare resources and the unemployment rate was assumed as a proxy of economic crisis. Hausman test showed that to perform the analysis it is required to use a random effect panel data model from 2005 to 2013. The data were taken from the World Bank database and the calculations were performed using the statistical software STATA 12.

Results: The results showed that the unemployment rate and out-of-pocket payment (OOP) had a strong relationship with healthcare resources. So, a $1 \%$ increase in unemployment rate leads a \$ 138 decrease in health expenditure per capita and a $1 \%$ increase in OOP is accompanied with a $\$ 12$ decrease in health expenditure per capita (p-value < 0.01). In this regard, countries having an unemployment rate more than 5\% and OOP more than $25 \%$ indicate $\$ 260$ health expenditure per capita less than countries with OOP less than $25 \%$ and an unemployment rate less than $5 \%$.

Conclusions: The findings imply that during the economic crisis there is a decrease in healthcare resources for Eastern Mediterranean countries. In this connection, the unemployment rate and OPP are important predictors of healthcare resources.
\end{abstract}

\section{Introduction}

Healthcare systems are dynamic entities which are able to translate financial resources into health outcomes, to assist the population they are entitled to serve. ${ }^{1}$ Most studies have been classified affecting factors on healthcare resources into two groups; economic variables and variables related to the health system. The unemployment rate is one of the macroeconomic variables on social welfare. ${ }^{2,3}$ The relationship between unemployment and health has gone beyond the financial effects. Many studies have examined the relationship between unemployment and health, where a strong negative relationship is reported between the health of individuals and unemployment or between the health and loss of income. ${ }^{4-6}$ For instance, a report in European countries of the WHO indicated that with a decrease in the Gini coefficient, the death rate due to suicide declined. ${ }^{7}$ A study by Stuckler et al. in Europe show a $1 \%$ increase in unemployment rate was associated with a $0.79 \%$ rise in suicide at ages younger than 65 years. $^{8}$

According to the WHO reports, health expenditure per capita in Eastern Mediterranean Region is US\$ 50 to US\$ 900, as a whole, approximately US\$ 125 billion was spent on health in 2011 in the Region, which constitutes $1.8 \%$ of the total world health expenditure for approximately $8.7 \%$ of the world population. This discrepancy is explained by the fact that almost $40 \%$ of regional expenditure is OOP. ${ }^{9,10}$

In recent decades, economic crises have created many problems in developing countries. Particularly in the Eastern Mediterranean region, where the economic crisis is coupled with political crises, as a result of an economic crisis, there are several impacts at both the nation and individual levels characterized by a decrease in economic growth and a fall at real household income and tax revenues, leading to a poor health status. $^{11}$

Although many studies have been conducted over the past decade on the relationship between healthcare resources and economic crisis,

\footnotetext{
* Corresponding author.

E-mail address: javadjavan.n@gmail.com (J. Javan-Noughabi).
} 
few of them were done on the basis developing counties and Eastern Mediterranean countries. Therefore, in the present research, we designed a panel data study about the impact of economic crisis on healthcare resources in Eastern Mediterranean countries.

\section{Methods}

To develop a retrospective panel, we collected annual data for 19 member countries of WHO in the Eastern Mediterranean Region during 2005 to 2013. These countries are Afghanistan, Bahrain, Arab Republic of Egypt, Islamic Republic of Iran, Iraq, Jordan, Kuwait, Lebanon, Libya, Morocco, Oman, Qatar, Pakistan, Saudi Arabia, Sudan, Syrian Arab Republic, Tunisia, United Arab Emirates, and the Republic of Yemen.

The economic data (unemployment rate) were taken from the World Bank database and International Labor Organization (ILO), which defines unemployment as all people who were without work yet available for or seeking employment. ${ }^{12}$ In this study, we used the logarithm of the unemployment rate.

According to a database of World Bank, health expenditure capita is the sum of public and private health expenditures as a ratio of total population, and this variable is as purchasing power parity. ${ }^{13}$ OOP expenditure is any direct outlay by households, including gratuities and in-kind payments, to health practitioners and suppliers of pharmaceuticals, therapeutic appliances, and other goods and services whose primary intent is to contribute to the restoration or enhancement of the health status of individuals or population groups. ${ }^{14} \mathrm{OOP}$ is a part of private health expenditure and in this study is as a percentage of total health expenditure. The calculations were performed using the statistical software STAT 12.

We started our research with a descriptive analysis, which would allow us to explore the data and identify the specific trend of the study's variables. Subsequently, a correlation analysis provided us with the information about the degree of association between the quantitative variables.

To assess the association between healthcare resources and the unemployment rate, we would perform a regression analysis by ordinary least square (OLS) criterion to identify the impact of the unemployment rate on the healthcare resources. Because Hausman test showed that we could not use fixed effects model, we used randomeffects approach.

We considered the rate of unemployment (\%), as a proxy for the recession and considered health expenditure per capita as healthcare resources.

Regarding that, the health financing systems is an important predictor of healthcare resources, and health system financing in Eastern Mediterranean countries is mostly OOP, we would consider OOP, as a proxy for health care financing. According to the threshold considered for OOP, we divided countries into two groups: with OOP less than $25 \%$ and OOP higher than $25 \%{ }^{15}$

Next, we performed a correlation analysis to evaluate the degree of association between the unemployment rate and the variables of healthcare resources, by calculating Spearman's coefficient. This elementary analysis would allow a comparison with the results already obtained by other researchers in connecting the same issues.

Finally, we ran a multivariate regression analysis with OLS, which is a random effects model. As the first step, Eq. (1) was applied, where $Y_{i t}$ is the dependent variable and shows health expenditure per capita in the time $t$ and in country $i$ and $X_{i t}$ is unemployment rate, $E_{i t}$ is OOP as a percentage of total health expenditure.

$Y_{\text {it }}=a_{0}+a_{1} X_{i t}+a_{2} E_{i t}+e$
$Y_{i t}=a_{0}+a_{1} X_{i t}+a_{2} E_{i t}+e$
$Y_{i t}=a_{0}+a_{1} X_{i t}+a_{2} E_{i t}+a_{3} X_{i t} E_{i t}+e$
Table 1

Summary statistics of the variables considered in the research, for the 19 country in the Eastern Mediterranean Region, from 2005 t0 2013.

\begin{tabular}{lllll}
\hline Variable & Mean & $\begin{array}{l}\text { Standard } \\
\text { deviation }\end{array}$ & Minimum & Maximum \\
\hline Unemployment rate & 9.46 & 5.11 & 0.54 & 18.87 \\
$\begin{array}{l}\text { Health expenditure per capita } \\
\begin{array}{c}\text { Out of pocket (\% total health } \\
\text { expenditure) }\end{array}\end{array}$ & 474 & 487 & 34.9 & 1806 \\
& & 20.88 & 11.92 & 76.05 \\
\hline
\end{tabular}

In Eq. (2), $E_{i t}$ indicates the OOP, which is a dummy variable that divides countries into two groups: OOP less than $25 \%$ and OOP more than $25 \%$.

Furthermore, we would consider synergistic effects of the unemployment rate and health system financing on healthcare resources by Eq. (3). For this purpose, we will use a dummy variable $\left(\mathrm{X}_{\mathrm{it}} \mathrm{E}_{\mathrm{it}}\right)$. If unemployment rate is less than $5 \%$ and OOP is less than $25 \%$, then dummy variable $=0$; if unemployment rate is more than $5 \%$ and OOP is less than $25 \%$, then dummy variable $=1$; if unemployment rate is more than $5 \%$ and OOP is more than $25 \%$, then dummy variable $=2$; and for other cases dummy variable $=3$.

\section{Results}

According to Table 1, during the period 2005 to 2013, the average of the unemployment rate was 9.46 (5.11) for the 19 countries of WHO's Eastern Mediterranean Region, the minimum being 0.54 for Qatar and the maximum being 18.87 for Libya. The mean of OOP as a percentage of total health expenditure was 40.49 (20.88), with the maximum and the minimum values being 76.05 for Afghanistan and 34.9 for Oman, respectively. The average health expenditure per capita was \$ 474 USA, between 2005 and 2013. The minimum value of $\$ 34.9$ was observed for Pakistan and the highest value of $\$ 1806$ was attained for Qatar.

Considering the correlation analysis results (Table 2), we can observe an average negative association between the unemployment rate and health expenditure per capita. As can be seen, the Spearman's correlation coefficient is -0.54 ( $\mathrm{p}<0.001$ ) between the unemployment rate and health expenditure per capita. To consider the correlation between unemployment rate and OOP payment, we can observe a positive association $(0.48, \mathrm{p}<0.001)$.

The descriptive analysis (Fig. 1) shows that the trend of OOP and unemployment rate has a similar pattern. In the countries with OOP $>25$, the average unemployment rate is higher. Also, in the countries with a lower OOP, there is a lower unemployment rate.

According to Eq. (1) (Table 3), there is a statistically significant relationship between unemployment rate and health expenditure per capita, such that a $1 \%$ increase in unemployment rate leads to a \$138 decrease in health expenditure per capita (Model 1). Also, there is a statistically significant $\$ 12$ (p < 0.001) decrease in health expenditure per capita that is associated with a $1 \%$ increase in OOP.

According to Model 2 (Table 3), countries with an OOP higher than $25 \%$, on average, have $\$ 167$ less health expenditure per capita compared with counties with OOP lower than $25 \%$.

Our results demonstrate that significant synergetic effect of the unemployment rate and OOP (Model 3), such that countries with an

Table 2

Spearman's correlation coefficient between unemployment rate and health expenditures.

\begin{tabular}{ll}
\hline & Unemployment rate \\
\hline Health expenditure per capita & $-0.54^{* * *}$ \\
Out of pocket (\% total health expenditure) & $0.48^{* * *}$ \\
\hline
\end{tabular}

$* * \mathrm{p}<0.001$ 


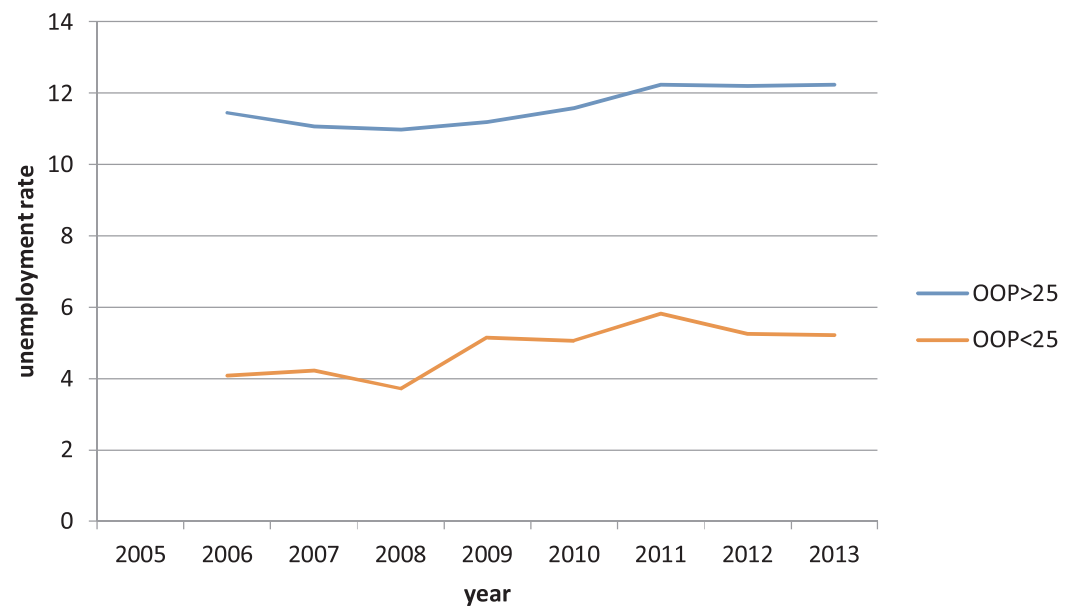

Fig. 1. Unemployment rate according to out of pocket in the Eastern Mediterranean Region of the World Health Organization.

Table 3

The results of estimating the model with OLS random effects.

\begin{tabular}{|c|c|c|c|}
\hline & Model 1 & Model 2 & Model 3 \\
\hline Constant & $\begin{array}{l}1238.61^{* *} \\
(102.68)\end{array}$ & $\begin{array}{l}895.32^{* * *} \\
(111.14)\end{array}$ & $\begin{array}{l}1329.62^{* * *} \\
(97.65)\end{array}$ \\
\hline Log Unemployment rate & $\begin{array}{l}-138.78 \\
(42.52)\end{array}$ & $\begin{array}{l}-159.12^{\text {k* }} \\
(47.81)\end{array}$ & $-91.88^{*}(44.52)$ \\
\hline $\mathrm{OOP}$ & $-12.26^{\text {*t. }}(1.80)$ & $\begin{array}{l}-167.82^{*} \\
(53.07)\end{array}$ & $-11.51^{\text {*kik }}(2.04)$ \\
\hline \multicolumn{4}{|l|}{ Unemployment OOP } \\
\hline $\mathrm{OOP}<25, \mathrm{U}>5$ & & & $\begin{array}{l}-306.35^{k * k} \\
(86.23)\end{array}$ \\
\hline $\mathrm{OOP}>25, \mathrm{U}>5$ & & & $\begin{array}{l}-260.39^{*} \\
(93.72)\end{array}$ \\
\hline $\mathrm{OOP}>25, \mathrm{U}<5$ & & & $-84.48(79.02)$ \\
\hline $\mathrm{R}^{2}$ & 0.74 & 0.74 & 0.81 \\
\hline Hausman test & 0.09 & 0.21 & 0.5 \\
\hline
\end{tabular}

()Standard error.

* $\mathrm{p}<0.05$

$* * \mathrm{p}<0.001$

unemployment rate more than 5\% and OOP more than $25 \%$ have $\$ 260$ less health expenditure per capita than countries with OOP less than $25 \%$ and an unemployment rate less $5 \%$.

Our research shows that unemployment rate and OOP are significant predictors of healthcare resources. As shown in Table 3, the coefficient of determination $\left(\mathrm{R}^{2}\right)$ for Models 1 and 2 is 0.74 while it is 0.81 for Model 3.

\section{Discussion}

About 30 years ago, Newhouse's conducted a study to compare health spending across countries. ${ }^{16}$ Since then, the factors affecting the health expenditure per capita have created great interest among economists. In studies after Newhouse's, macroeconomics variables and predictors related to the healthcare system have been mentioned as effective variables on health spending per capita. ${ }^{17,18}$

The present research is the first cross-country study on the Eastern Mediterranean Region of the WHO to assess the effects of the economic crisis on healthcare resources. According to descriptive findings, we found the mean health expenditure per capita of \$ 474 US in 2005-2013 in the Eastern Mediterranean countries, with the minimum value of $\$ 34.9$ for Pakistan and the highest value of $\$ 1806$ for Qatar. Compared with results reported by Organization for Economic Co-operation and Development (OECD), health expenditure per capita is low in EMRO. For instance, the average health expenditure per capita in the USA is the highest among OECD and increased from \$ 6037 to \$ 7212 in a period of 2004-2011. ${ }^{13,19}$ Among the countries of OECD, Mexico with \$ 562 has the lowest health expenditure per capita, which is significantly different compared with countries in EMRO, where the mean of health spending per capita was $\$ 474 .{ }^{19}$

Our results indicate that unemployment rate is an important predictor of healthcare resources such that a $1 \%$ increase in unemployment rate is accompanied by a \$138-159 decrease in health expenditure. Studies have reported that unemployment rate has a negative relation with healthcare resources. ${ }^{11,20}$

Our results show that the mean of OOP is $40 \%$ (as a percentage of total health expenditure) for Eastern Mediterranean countries. Also, the funding of regression demonstrated that OOP is an influential factor on healthcare resources. In this regard, there is a statistically significant \$ 12 decrease $(p<0.001)$ in health expenditure per capita that is associated with a $1 \%$ increase in OOP as a percentage of total health expenditures. In other words, in countries with healthcare systems financed by OOP (more than $25 \%$ ), there is an average of \$ 167 less spent for health expenditure per capita.

OOP is one of the financing methods that reduced household's welfare. Studies have indicated that the mean of OOP in the world was $24 \%$. This method makes families faced with catastrophic healthcare expenditure and reduced health expenditure per capita. ${ }^{21-24} \mathrm{~A}$ study in Indiana has shown that an increase in OOP leads to catastrophic health expenditure and households go into poverty, such that households postpone their treatment and ultimately reduce health expenditure per capita. $^{25,26}$

In this study, we consider synergistic effects OOP and unemployment rate. Thus, our results indicated that countries with unemployment rate more than $5 \%$ and OOP more than $25 \%$, have $\$ 260$ health expenditure per capita less than countries with OOP less than $25 \%$ and unemployment rate less $5 \%$. Although, to the best of authors' knowledge, there is no study in the literature that considers the synergistic effect of two variables (unemployment rate and OOP) on health expenditure per capita, we expect a sharp decline in health spending per capita as a result of the cumulative effect. The main explanation for this observation is that the rising unemployment rate will limit having access to finance resource, on one hand, and OOP by imposing households to catastrophic health spending will bring them below the poverty line, on the other hand.

While our study contributes to a better understanding of the impact of economic crisis on healthcare resources, it does have important limitations. First, if the period of study was longer (more than 10 years), the impact of the unemployment rate and OOP payment could be better explored because the effect of economic crisis appears over the longer periods of time. Second, we divided the health system of countries based on the amount of OOP payment, it is much better to have the 
health system of countries according to financing.

\section{Conclusion}

Our results have shown that mean of the unemployment rate is high in Eastern Mediterranean countries during the decade from 2005 to 2013. Also, during the economic crisis, a decline in funding for the health system occurred. We found that, during the economic crisis, there is a further reduction on health care resource in countries where the health system is financed through OOP.

\section{Conflict of interest}

None.

\section{References}

[1]. Labonté R. The global financial crisis and health: scaling up our effort. Can J Public Health/Revue Canadienne de Sante'e Publique. 2009:173-175.

[2]. Grogger J. Welfare transitions in the 1990: the economy, welfare policy, and the EITC. J Policy Anal Manage. 2004;23(4):671-695.

[3]. Ruhm CJ. Commentary: mortality increases during economic upturns. Int $J$ Epidemiol. 2005;34(6):1206-1211.

[4]. Adams P, Hurd MD, McFadden D, Merrill A, Ribeiro T. Healthy, wealthy, and wise? Tests for direct causal paths between health and socioeconomic status. $J$ Econom. 2003;112(1):3-56

[5]. Rogot E, Sorlie PD, Johnson NJ. Life expectancy by employment status, income, and education in the National Longitudinal Mortality Study. Public Health Rep. 1992;107(4):457

[6]. Singh GK, Siahpush M. Inequalities in US life expectancy by area unemployment level, 1990-2010. Scientifica. 2016;2016.

[7]. Organization WH. Impact of economic crises on mental health. Impact of economic crises on mental health. 2011; 2011

[8]. Stuckler D, Basu S, Suhrcke M, Coutts A, McKee M. The public health effect of economic crises and alternative policy responses in Europe: an empirical analysis. The Lancet. 2009;374(9686):315-323.

[9]. Analysis of the private health sector in countries of the Eastern Mediterranean. Nasr City: World Health Organization, Regional Office for the Eastern Mediterranean, P.
O. Box 7608, Nasr City, Cairo 11371, Egypt (2014).

[10]. WHO global health expenditure database. http://apps.who.int/nha/database/ DataExplorerRegime.aspx.

[11]. Hopkins S. Economic stability and health status: evidence from East Asia before and after the 1990 economic crisis. Health Policy. 2006;75(3):347-357.

[12]. Bartley M. Unemployment and ill health: understanding the relationship. $J$ Epidemiol Commun Health. 1994;48(4):333-337.

[13]. Lorenzoni L, Belloni A, Sassi F. Health-care expenditure and health policy in the USA versus other high-spending OECD countries. The Lancet. 2014;384(9937):83-92

[14]. WHO global health expenditure database. http://apps.who.int/nha/database for the most recent updates.

[15]. Van Doorslaer E, O'Donnell O, Rannan-Eliya RP, et al. Paying out-of-pocket for health care in Asia: catastrophic and poverty impact. Rotterdam and IPS, Colombo: Erasmus University; 2005.

[16]. Newhouse JP. Medical-care expenditure: a cross-national survey. J Hum Resour. 1977;12(1):115-125.

[17]. Magazzino C, Mele M. The determinants of health expenditure in Italian regions. 2012; 2012

[18]. Di Matteo L. The macro determinants of health expenditure in the United States and Canada: assessing the impact of income, age distribution and time. Health Policy. 2005;71(1):23-42.

[19]. Baltagi BH, Moscone F. Health care expenditure and income in the OECD reconsidered: evidence from panel data. Econ Modell. 2010;27(4):804-811.

[20]. Portela C, Thomas S. Impact of the economic crisis on healthcare resources: An European approach. International Journal of Healthcare Management 2013;6(2):104-113.

[21]. Organization WH, The work of WHO in the Eastern Mediterranean Region: annual report of the Regional Director, 1 January-31 December 2004, 2005.

[22]. Garg CC, Karan AK. Reducing out-of-pocket expenditures to reduce poverty: disaggregated analysis at rural-urban and state level in India. Health Policy Plann. 2008;24(2):116-128

[23]. Yardim MS, Cilingiroglu N, Yardim N. Catastrophic health expenditure and impoverishment in Turkey. Health Policy. 2010;94(1):26-33.

[24]. Ayé R, Wyss K, Abdualimova H, Saidaliev S. Illness costs to households are a key barrier to access diagnostic and treatment services for tuberculosis in Tajikistan. BMC Res Notes. 2010;3(1):340.

[25]. Van Doorslaer E, O'Donnell O, Rannan-Eliya RP, et al. Effect of payments for health care on poverty estimates in 11 countries in Asia: an analysis of household survey data. The Lancet. 2006;368(9544):1357-1364.

[26]. Wagstaff A, Doorslaer Ev. Catastrophe and impoverishment in paying for health care: with applications to Vietnam 1993-1998. Health Econ. 2003;12(11):921-933. 